\title{
Detection of Drug Susceptibility to Azoles among Trichophyton rubrum Isolates by Disk Diffusion Method
}

\author{
G M Mohiuddin'1, Humayun Sattar ${ }^{1}$, Ahmed Abu Saleh'1, Abu Naser Ibne Sattar ${ }^{1}$, S M Ali Ahmed ${ }^{1}$ \\ Fatima Afroz ${ }^{1}$, Mashrura Quraishi' ${ }^{1}$
}

${ }^{1}$ Department of Microbiology and Immunology, Bangabandhu Sheikh Mujib Medical University

\begin{abstract}
Dermatophytes are filamentous fungi that cause tiniasis with high prevalence in tropical hot, humid and overcrowded countries like Bangladesh. Antifungal drug resistance among dermatophyte isolates are very common due to irrational and overuse of them. In vitro antifungal susceptibility test may help to select appropriate drug, optimize the therapy and monitor the emergence of drug resistance. This study was undertaken to isolate and identify different dermatophyte species from skin, nail and hair samples and to see the susceptibility pattern of azoles (fluconazole, miconazole and itraconazole) among one of the most common dermatophyte isolates (Trichophyton rubrum) by disk diffusion method. A total of two hundred and forty six patients clinically suspected of dermatophytosis attending in the outpatient department (OPD) of Dermatology and Venereology of BSMMU, Dhaka, were studied from September 2018 to August 2019. All the samples of skin, nail and hair were processed for direct microscopic examination and culture. The species of dermatophytes were identified by gross colony morphology, microscopic features and biochemical tests. Antifungal susceptibility was performed by disk diffusion (Neo-Sensitabs susceptibility testing modified for Dermatophytes) method in Sabouraud's dextrose agar (SDA) media. Out of 246 specimens $27.2 \%$ were positive by microscopy, $28.9 \%$ were positive by culture and $26.0 \%$ were positive by both microscopy and culture. Tinea cruris (32.4\%) was the most prevalent clinical type among all dermatophyte isolates. Among 71 culture positive isolates, T. rubrum (71.8\%) was most prevalent followed by T. mentagrophytes (24.0\%) and E. floccosum (4.2\%). By disk diffusion method fluconazole was found as the most resistant drug (90.2\%) against $T$. rubrum isolates and Itraconazole was the most sensitive (80.4\%). Miconazole was found as most intermediate sensitive.
\end{abstract}

Key words: Dermatophytes, Tineasis, Antifungal susceptibility test, Disk diffusion.

\section{Introduction}

Dermatophytes are pathogenic fungi having a high affinity for keratinized structures like skin, hair or nail causing superficial infections known as dermatophytosis. They belong to three genera- Trichophyton, Epidermophyton and Microsporum and cause clinical lesions named tineasis. ${ }^{1,2}$ Dermatophytosis is most common in Tropical and Subtropical countries. In Bangladesh hot and humid climate, overcrowded population, poverty and malnutrition make dermatophytosis a very common superficial infection. ${ }^{3}$ Study conducted worldwide showed that antifungal resistance of dermatophytosis very common particularly against azoles drug group due to irrational and overuses of them.

Correspondence:

Dr. G. M. Mohiuddin

Department of Microbiology and Immunology

Bangabandhu Sheikh Mujib Medical University, Dhaka.

Phone : 01718549767

E-mail: sohanmmc74@gmail.com
In vitro antifungal susceptibility testing could be helpful in the better management of the dermatophytosis. ${ }^{4,5}$ Recently, the Clinical and Laboratory Standard Institute (CLSI) announced the availability of a new standard guideline on antifungal disk diffusion susceptibility testing of yeast, M44-A in 2004, where in vitro testing of molds and dermatophytes was not addressed. ${ }^{6}$ of the several commercial systems now the disk diffusion Neo-Sensitabs method is of potential value for dermatophytes. This method has proven to be useful in testing yeasts and it has been modified to evaluate dermatophyte fungi. ${ }^{7}$

This study was aimed to isolate and identify different dermatophyte species from skin, nail and hair specimen and to determine the susceptibility pattern of azoles (fluconazole, miconazoles and itraconazole) against Trichophyton rubrum isolates by disk diffusion method.

\section{Materials and Methods:}

The study was carried out from September 2018 to 
August 2019. A total of 246 patients attending in the outpatient department of Dermatology and Venereology of BSMMU, Dhaka, clinically suspected of having dermatophytosis of skin, nail and hair were included in this study. All samples were screened by direct microscopy for presence of fungal elements by treating them with $20 \% \mathrm{KOH}$ and culture performed in Dermatophyte test media (DTM) with supplements (Cycloheximide, chlortetracycline and gentamicin) (HiMedia, India) at $25-30^{\circ} \mathrm{C}$ for 21 days. Growth of dermatophytes changed the color of DTM from yellow to red. Species of dermatophytes were identified by observing the colonial morphology in culture by tease mount microscopy test and biochemical tests (Urease test and hair perforation test). The dermatophyte isolates were preserved in screw capped test tube containing $5 \mathrm{ml}$ distilled water at $4^{\circ} \mathrm{C}$ with proper labeling and date of preservation.

Preparation of inocula: The isolates were transferred from distilled water stocks to potato dextrose agar (PDA) (HiMedia, India) media at $25-30^{\circ} \mathrm{C}$ to enhance conidial growth. Seven days old culture was covered with $10 \mathrm{ml}$ $0.9 \%$ normal saline and the colonies were scraped with the tip of a sterile wire loop to obtain a mixture of mycelium and conidia. The suspension was transferred to a sterile test tube and allowed to sediment the heavy particles for 5-10 minutes. The upper homogenous suspension was taken and transferred to another sterile test tube and adjusted to $0.5 \mathrm{McF}$ arland standard visually against a card with white background and contrasting black lines.

Antifungal disk: The antifungal disks were purchased (Biomaxima, Poland) with following potencies: Fluconazole $25 \mu \mathrm{g} /$ disk, miconazole $10 \mu \mathrm{g} /$ disk and itraconazole $8 \mu \mathrm{g} /$ disk.

Disk diffusion assay: The disk diffusion method was done according to Neo-Sensitabs susceptibility testing (2002) method modified for dermatophytes 7 . Within 15 minutes of adjusting the turbidity of inoculum, a sterile cotton swab was dipped into the suspension, rotating and pressing firmly against the inside wall of the tube above the fluid level to remove excess fluid from the swab. The dried surface of a sterile Sabouraud dextrose agar (HiMedia, India) plate was inoculated by evenly streaking the swab over the entire agar surface. The antifungal disks were applied evenly. The plates were incubated at $25^{\circ} \mathrm{C}$ for 5-10 days. After the colonies being grown the zones of inhibition around the disks were measured and recorded.
Table-I: Zone diameters for antifungal drug susceptibility by disk diffusion method:

\begin{tabular}{lcccc}
\hline Antifung & Disk & \multicolumn{3}{c}{ Zone diameter in mm } \\
\cline { 3 - 5 } al drugs & Potency & Sensitive & Intermediate & Resistance \\
& & & & \\
\hline Fluconazole & $25 \mu \mathrm{g}$ & $\geq 22$ & $21-15$ & $\leq 14$ \\
Miconazole & $10 \mu \mathrm{g}$ & $\geq 20$ & $19-12$ & $\leq 11$ \\
Itraconazole & $8 \mu \mathrm{g}$ & $\geq 15$ & $14-10$ & $\leq 10$ \\
\hline
\end{tabular}

Ethical consideration: The study was ethically approved by Institutional Review Board (I.R.B), BSMMU (Reference NO. BSMMU/2019/1224 Date: 06/02/2019).

\section{Results:}

Out of 246 clinically suspected cases 67 (27.2\%) were found as positive by direct microscopy and 71 (28.9\%) were culture positive and $64(26.0 \%)$ were both microscopy and culture positive. Three (1.2\%) specimens were found as microscopy positive only and 7 (2.9\%) were culture positive only (Table II).

Table-II: Distribution of microscopy and culture positivity among all specimens $(n=246)$

\begin{tabular}{llll}
\hline & $\begin{array}{l}\text { Culture } \\
\text { positive }\end{array}$ & $\begin{array}{l}\text { Culture } \\
\text { negative }\end{array}$ & Total \\
\hline $\begin{array}{l}\text { Microscopy } \\
\text { positive }\end{array}$ & $64(26.0 \%)$ & $3(1.2 \%)$ & $67(27.2 \%)$ \\
$\begin{array}{l}\text { Microscopy } \\
\text { negative }\end{array}$ & $7(2.9 \%)$ & $172(69.9 \%)$ & $179(72.8 \%)$ \\
$\begin{array}{l}\text { Total } \\
71(28.9 \%)\end{array}$ & $175(71.1 \%)$ & $246(100.0 \%$ \\
\hline
\end{tabular}

Among 71 dermatophyte isolates, 23 Tinea cruris (32.4\%) was found as most common clinical types followed by Tinea corporis 22 (31.0\%), Tinea unguium 12 (16.9\%), Tinea pedis 9 (12.7\%), Tinea capitis 4 (5.6\%) and Tinea mannum 1(1.4\%). Out of 71 culture positive isolates most 51 (71.8\%) were Trichophyton rubrum followed by Trichophyton mentagrophytes $17(24.0 \%)$ and Epidermophyton floccosum 3 (4.2\%) (Table III). 
Table-III: Distribution of dermatophyte isolates from different clinical types of samples $(n=71)$

\begin{tabular}{|c|c|c|c|c|}
\hline $\begin{array}{c}\text { Clinical } \\
\text { types }\end{array}$ & $\begin{array}{l}\text { Number } \\
\text { of } \\
\text { culture } \\
\text { positive } \\
\text { isolates }\end{array}$ & T. rubrum & $\begin{array}{l}\text { T. mentag- } \\
\text { rophytes }\end{array}$ & E. floccosum \\
\hline $\begin{array}{c}\text { Tinea } \\
\text { capitis }\end{array}$ & $\begin{array}{c}4 \\
(5.6 \%)\end{array}$ & $\begin{array}{c}1 \\
(25.0 \%)\end{array}$ & $2(50.0 \%)$ & $\begin{array}{c}1 \\
(25.0 \%)\end{array}$ \\
\hline $\begin{array}{l}\text { Tinea } \\
\text { faciei }\end{array}$ & $\begin{array}{c}0 \\
(0.0 \%)\end{array}$ & $\begin{array}{c}0 \\
(0.0 \%)\end{array}$ & $0(0.0 \%)$ & $0(0.0 \%)$ \\
\hline $\begin{array}{c}\text { Tinea } \\
\text { corporis }\end{array}$ & $\begin{array}{l}22 \\
(31.0 \%)\end{array}$ & $\begin{array}{c}16 \\
(72.7 \%)\end{array}$ & $4(18.2 \%)$ & $2(9.1 \%)$ \\
\hline $\begin{array}{c}\text { Tinea } \\
\text { manиum }\end{array}$ & $\begin{array}{c}1 \\
(1.4 \%)\end{array}$ & $\begin{array}{c}1 \\
(100.0 \%)\end{array}$ & $0(0.0 \%)$ & $0(0.0 \%)$ \\
\hline $\begin{array}{l}\text { Tinea } \\
\text { cruris }\end{array}$ & $\begin{array}{c}23 \\
(32.4 \%)\end{array}$ & $\begin{array}{c}17 \\
(73.9 \%)\end{array}$ & $6(26.1 \%)$ & $0(0.0 \%)$ \\
\hline $\begin{array}{l}\text { Tinea } \\
\text { pedis }\end{array}$ & $\begin{array}{c}9 \\
(12.7 \%)\end{array}$ & $\begin{array}{c}8 \\
(88.9 \%)\end{array}$ & $1(11.1 \%)$ & $0(0.0 \%)$ \\
\hline $\begin{array}{c}\text { Tinea } \\
\text { unguium }\end{array}$ & $\begin{array}{c}12 \\
(16.9 \%)\end{array}$ & $\begin{array}{c}8 \\
(66.7 \%)\end{array}$ & $4(33.3 \%)$ & $0(0.0 \%)$ \\
\hline Total & $71(100.0 \%)$ & $51(71.8 \%)$ & $17(24.0 \%)$ & $3(4.2 \%)$ \\
\hline
\end{tabular}

T=Trichophyton, E=Epidermophyton

Table IV showed the antifungal susceptibility of Trichophyton rubrum isolates against fluconazole, miconazole and itraconazole by disk diffusion method. Among 51 isolates, fluconazole was found as most resistant drug $(90.2 \%)$ followed by miconazole $(13.7 \%)$. Itraconazole was found as most sensitive drug $(80.4 \%)$ followed by and miconazole $(60.8 \%)$. Intermediate sensitivity against miconazole was found as $25.5 \%$ followed by itraconazole $(11.8 \%)$ and fluconazole $(7.8 \%)$.

Table-IV: Antifungal susceptibility of Trichophyton rubrum isolates by disk diffusion method $(n=51)$

\begin{tabular}{lll}
\hline \multicolumn{2}{c}{ Antifungal drug } & $\begin{array}{l}\text { Trichophyton } \\
\text { rubrum }\end{array}$ \\
\hline Fluconazole & Sensitive & $1(2.0 \%)$ \\
& Intermediate & $4(7.8 \%)$ \\
& Resistance & $46(90.2 \%)$ \\
Miconazole & Sensitive & $31(60.8 \%)$ \\
& Intermediate & $13(25.5 \%)$ \\
& Resistance & $7(13.7 \%)$ \\
Itraconazole & Sensitive & $41(80.4 \%)$ \\
& Intermediate & $6(11.8 \%)$ \\
& Resistance & $4(7.8 \%)$ \\
\hline
\end{tabular}

Discussion

Superficial fungal infections are very common in tropical countries like Bangladesh. Among them the most common type is dermatophytosis. Due to irrational and over use, drug resistance is a very common matter. In vitro antifungal susceptibility test may help to select appropriate drug, optimize the therapy and monitor the emergence of drug resistance. ${ }^{3}$ This study was undertaken to identify different dermatophyte species and to see the susceptibility pattern of azoles (fluconazole, miconazole and itraconazole) among Trichophyton rubrum isolates. Among 246 specimens $27.2 \%$ were positive by microscopic examination which is comparable with other studies. 3,8 This result is considered as higher than $14.3 \% 9$ and lower compared to $45.5 \% .^{10}$ In present study $28.9 \%$ cases were found as culture positive which are comparable with previous studies. ${ }^{3,8}$ This is slightly lower than 43\%. ${ }^{11}$ Higher or lower isolation rates from clinical specimens depends on different factors like collection of specimens, composition and $\mathrm{pH}$ of the media, incubation period and temperature, viability of fungal elements and co-existing microbes which may inhibit the growth of pathogenic fungi.

In this study, among all culture positive dermatophyte isolates Tinea cruris $(32.4 \%)$ was found as most common clinical types followed by Tinea corporis $(31.0 \%)$ and Tinea unguium (16.9\%). These findings were not similar with a previous study from South India where highest incidence of Tinea corporis (35.4\%) was reported followed by Tinea cruris (16.76\%) and Tinea capitis $(16.6 \%){ }^{12}$ Another stydy in North East India reported highest incidence of Tinea pedis $(29.2 \%)$ followed by Tinea cruris $(26.2 \%){ }^{13}$ These variations in the site of infection between this study and others may be due to geographical variations, nature of the job, the number of study population, cultural variation and hygienic condition. In this study, among 71 culture positive samples T. rubrum was found as commonest dermatophyte isolates (71.8\%) followed by T. mentagrophytes $17(24.0 \%)$ and E. floccosum 3 $(4.2 \%)$. These findings were consistent with previous study $^{3}$, where T. rubrum was found to be $86.6 \%$, T. mentagrophytes $8.2 \%$ and E. floccosum 5.2\%. Another study in West Rajasthan, India where T. mentagrophytes (41.3\%) was most prevalent followed by T. rubrum (17.3\%), T. tonsurans (16\%), T. verrucosum (12\%) and E. floccosum $(5.3 \%) .{ }^{14}$

By disk diffusion method, among 51 T. rubrum isolates 90.2\% were resistant to fluconazole followed by miconazole (13.7\%). Among them itraconazole $(80.39 \%)$ was found as most sensitive $(92.2 \%)$ followed by miconazole $(60.78 \%)$. Intermediate sensitivity of miconazole was $25.5 \%$. This result was comparable with 
a study in Bangladesh where fluconazole was reported as most resistant $(95 \%)$ and Itraconazole $(92.5 \%)$ as most sensitive $(97.5 \%)$ among azole drugs among T. rubrum isolates. ${ }^{3}$ But their study did not include miconazole. A recent study in India reported that $T$. rubrum isolates were $38.46 \%$ resistant against fluconazole. ${ }^{14}$

\section{Conclusion}

In vitro susceptibility showed that among three azoles tested; fluconazole had shown the highest resistance rate. Itraconazole was found to be the most sensitive drug followed by miconazole. Itraconazole can be used to treat most of the T. rubrum infections particularly those who show resistance to fluconazole. Antifungal sensitivity should be evaluated before prescribing miconazole.

\section{Acknowledgement}

The work was supported financially by the Thesis Grant Committee, Bangabandhu Sheikh Mujib Medical University, Dhaka.

\section{Conflict of interest}

We do not have any potential conflicts of interest.

\section{References}

1. Coelho LM, Aquino-Ferreira R, Maffei CM, MartinezRossi NM. In vitro antifungal drug susceptibilities of dermatophytesmicroconidia and arthroconidia. Journal of antimicrobial chemotherapy 2008 Jun 13;62(4):758-61.

2. Sabtharishi V, Katragadda R, Ravinder T. A study on the antifungal susceptibility pattern of dermatophytes isolated in a tertiary care hospital. International Journal of Bioassays 2017 May 6;6 (5):5379-82.

3. Rahim MR, Saleh AA, Miah MR, Anwar S, Rahman MM. Pattern of dermatophyte in Bangabandhu Sheikh Mujib Medical University. Bangladesh Journal of Medical Microbiology 2012 Jul 1;6(2):11-4.

4. Martinez-Rossi NM, Peres NT, Rossi A. Antifungal resistance mechanisms in dermatophytes. Mycopathologia 2008 Nov 1;166(5-6):369.

5. Bhatia VK, Sharma PC. Determination of minimum inhibitory concentrations of itraconazole, terbinafine and ketoconazole against dermatophyte species by broth microdilution method. Indian journal of medical microbiology 2015 Oct 1;33(4):533.
6. Esteban A, Abarca ML, Cabanes FJ. Comparison of disk diffusion method and broth microdilution method for antifungal susceptibility testing of dermatophytes. Medical mycology 2005 Feb 1;43(1):61-6.

7. Pakshir K, Bahaedinie L, Rezaei Z, Sodaifi M, Zomorodian K. In vitro activity of six antifungal drugs against clinically important dermatophytes. Jundishapur Journal of Microbiology 2009 Oct 1;2(4):158-63.

8. Islam TA, Majid F, Ahmed M, Afrin S, Jhumky T, Ferdouse F. Prevalence of Dermatophytic Infection and Detection of Dermatophytes by Microscopic and Culture Methods. Journal of Enam Medical College 2018 Feb 7;8(1):11-5.

9. Kam KM, Au WF, Wong PY, Cheung MM. Onychomycosis in Hong Kong. International journal of dermatology. 1997 Oct;36(10):757-61.

10. Kaur R, Kashyap B, Bhalla P. A five-year survey of onychomycosis in New Delhi, India: Epidemiological and laboratory aspects. Indian Journal of Dermatology 2007 Jan 1;52(1):39.

11. Sowmya N, Appalaraju B, Srinivas CR, Surendran P. Antifungal susceptibility testing for dermatophytes isolated from clinical samples by broth dilution method in a tertiary care hospital. JMR 2015;1:64-7.

12. Balakumar $S$, Rajan $S$, Thirunalasundari $T$, Jeeva $S$. Epidemiology of dermatophytosis in and around Tiruchirapalli, Tamilnadu, India. Asian Pacific Journal of Tropical Disease 2012 Aug 1;2(4):286-9.

13. Grover S, Roy P. Clinico-mycological profile of superficial mycosis in a hospital in North-East India. Medical Journal Armed Forces India 2003 Apr 1;59(2):114-6.

14. Khatri PK, Kachhawa D, Maurya V,Meena S, Bora A, Rathore L, Seervi KL, Khullar S. Antifungal resistance pattern among dermatophytes in Western Rajasthan. International Journal of Current Microbiology and Applied Sciences 2017;6:499-509. 